\title{
An Intentional Poisoning by Lormetazepam in a Patient Treated with Nordiazepam
}

\author{
Phak-Rop Pos Pok, Emilie Berland, Michel Mauras, Magali Valès, Erika Kuhlmann \\ Laboratoire de Police Scientifique de Marseille, Section Toxicologie, Institut National de Police Scientifique, \\ France \\ Email: rop-pos.pok@interieur.gouv.fr
}

Received 29 July 2014; revised 3 September 2014; accepted 23 September 2014

Copyright $@ 2014$ by authors and Scientific Research Publishing Inc.

This work is licensed under the Creative Commons Attribution International License (CC BY). http://creativecommons.org/licenses/by/4.0/

(c) (i) Open Access

\begin{abstract}
A case of suspected poisoning by benzodiazepines is presented in this paper. Toxicological analyses were applied on the blood collected 48 hours after the facts. GC-MS and HPLC-DAD have detected only nordiazepam which was prescribed in the treatment. Therefore, LC-MS/MS has detected lormetazepam and lorazepam (major metabolite of lormetazepam) in addition of nordiazepam. The concentrations of lormetazepam, lorazepam and nordiazepam measured in blood were $6.8,6.3$, and $16.2 \mathrm{ng} / \mathrm{mL}$, respectively. The initial concentration of each drug at the relevant time, has been calculated from these residual concentrations, using an extrapolation approach. According to estimates, only lormetazepam $(189 \mathrm{ng} / \mathrm{mL})$ and lorazepam $(68 \mathrm{ng} / \mathrm{mL})$, were active at the target moment. A poisoning by lormetazepam was then considered. The more technology we have, the greater chance we have to get an outcome that is favorable to justice.
\end{abstract}

\section{Keywords}

Benzodiazepines, Discrimination between Poison and Medication, LC-MS/MS

\section{Introduction}

Benzodiazepines are widely used in the treatment of insomnia and anxiety. The drugs share the same pharmacological properties such as anxiolytic and hypnotic. A common side effect of benzodiazepines is dose-related anterograde amnesia. Due to their side effects, they can be used for intentionally impairing or harming others. They are often used in combination with alcohol or other drugs for the purpose of robbery, physical assault, or sexual assault [1]. The intensity of the side effect depends on the nature of the benzodiazepine and its dosing. Generally, benzodiazepines with short elimination half-life and rapid onset of action, induce a greatest amnesic effect. The present study was conducted to a case where patient was suffering with alcohol withdrawal and was 
receiving nordiazepam for treatment. One day, patient falls deeply asleep. Toxic effects from nordiazepam and/ or other benzodiazepines were suspected. Identification and quantification of nordiazepam as well as other benzodiazepines in blood are of interest to understand toxic effects of the drugs. Given that sampling got belatedly (48 $\mathrm{h}$ after poisoning), it is important to have a sensitive method that is able to detect these types of drugs. Different methods have been reported for the determination of benzodiazepines in biological fluids [2]-[6]. Liquid chromatography coupled to tandem mass spectrometry (LC-MS/MS), seems like a very good way to obtain the desired detectability. In this study, identification and determination of these drugs are carried out by three procedures routinely applied in our laboratory (GC-MS [7], HPLC-DAD [7] and LC-MS/MS [8]). Quantitative data obtained from toxicological analysis help to estimate initial concentrations of the drugs as well as their degree of poisoning.

\section{History}

A 47-year-old woman was receiving Nordaz ${ }^{\circledR}$ (nordiazepam 7.5-mg tablets) since a year ago, to treat the symptom of alcohol withdrawal. What complicates the problem of this woman is that she does not take her medication regularly. One day, a visibly quarrel happened with spouse. She was discovered at home in drowsiness and confusion. She has lost touch with reality after severe symptoms and she has not been fully recovered. She is accusing her husband of trying to poison her with a drug. An admission to the emergency department has been required after she was able to recall what took place. After consultation of an intensivist physician she should be placed in the psychiatric ward in the hospital. Medical treatment was not needed. Only the oxygen therapy was used. Blood sample was collected at the moment for admitting. The average time elapsed between blood sampling and relevant moment was 48 hours.

\section{Materials and Methods}

The toxicological analysis was realized using the procedure routinely applied in our laboratory for the drug screening [7]. The sample preparation consisted of liquid-liquid extraction from the whole blood. The procedure uses an acid extraction ( $\mathrm{pH} 3$ ) and an alkaline extraction (pH 8.4), followed by chromatographic assays.

\subsection{Identification}

First, identification of drugs is carried out by gas chromatography-mass spectrometry (GC-MS) [7] and high performance liquid chromatography (HPLC-DAD) [7]. Chromatography equipment and devices were provided by Agilent Technologies. The methods have detected only nordiazepam that was the prescription medication. The major metabolite of nordiazepam (oxazepam) was not detected, the drug would be cleared from the blood. The test for ethanol and a toxicological screen for other toxics in the blood were negative.

In the second step, we used liquid chromatography coupled to tandem mass spectrometry (LC-MS/MS) for trying to detect drugs which were not detected in the first step. The analysis was performed on a Thermo Fisher Scientific system consisting of a liquid chromatography (LC Acella) equipped with a triple stage quadrupol mass spectrometry (TSQ Quantum Ultra). The chromatographic conditions were defined as those described by Thermo Fisher Scientific [6] [8], but with some modifications. The LC-MS/MS system has detected lormetazepam and lorazepam in addition of nordiazepam. Despite this, oxazepam remains undetectable.

\subsection{Quantification}

Lormetazepam, lorazepam and nordiazepam detected in blood, are then quantified simultaneously by LC-MS/ MS. The quantification of these drugs consisted of liquid-liquid extraction at pH 8.4 [7] from the whole blood. Deuterated lorazepam-d4 is used as internal standard to determine lormetazepam and lorazepam. Deuterated nordiazepam-d5 is used as internal standard to determine nordiazepam. To $1 \mathrm{~mL}$ of the blood to be analyzed, the corresponding internal standard solution in methanol $(10 \mu \mathrm{L}$ of $1 \mathrm{ng} / \mu \mathrm{L}$ for lorazepam-d4 or $25 \mu \mathrm{L}$ of $1 \mathrm{ng} / \mu \mathrm{L}$ for nordiazepam-d5), was added. After vortex-mixing, $1 \mathrm{~mL}$ of dipotassium phosphate $1 \mathrm{M}$ (pH 8.4) and $3 \mathrm{~mL}$ of chloroform/isopropanol (95:5, v/v) were added. The mixture was shaken for $10 \mathrm{~min}$ and centrifuged at 3000 rpm for $3 \mathrm{~min}$. The organic phase was removed and evaporated to dryness under nitrogen. The residue was reconstituted with $100 \mu \mathrm{L}$ of mobile phase. An aliquot of this solution $(10 \mu \mathrm{L})$ was injected into the LC-MS/MS. The parameters of transition of the analyzed compounds are shown in Table 1 . The method was linear over the 
Table 1. LC-MS/MS parameters.

\begin{tabular}{|c|c|c|c|c|c|}
\hline Drug & $\begin{array}{l}\text { Retention time } \\
\text { (min) }\end{array}$ & $\begin{array}{l}\text { Precursor ion } \\
\qquad(\mathrm{m} / \mathrm{z})\end{array}$ & $\begin{array}{l}\text { Product ions } \\
\qquad(\mathrm{m} / \mathrm{z})\end{array}$ & $\begin{array}{c}\text { Collision energy } \\
(\mathrm{eV})\end{array}$ & Tube lens (V) \\
\hline \multirow{3}{*}{ Nordiazepam } & \multirow{3}{*}{8.9} & \multirow{3}{*}{271} & 140 & 28 & \multirow{3}{*}{107} \\
\hline & & & 208 & 26 & \\
\hline & & & 165 & 28 & \\
\hline \multirow{3}{*}{ Nordiazepam-d5 } & \multirow{3}{*}{8.9} & \multirow{3}{*}{276} & 213 & 28 & \multirow{3}{*}{97} \\
\hline & & & 140 & 28 & \\
\hline & & & 165 & 29 & \\
\hline \multirow{2}{*}{ Lormetazepam } & \multirow{2}{*}{9.07} & \multirow{2}{*}{335} & 289 & 21 & \multirow{2}{*}{85} \\
\hline & & & 3 & 12 & \\
\hline \multirow{3}{*}{ Lorazepam } & \multirow{3}{*}{8.40} & \multirow{3}{*}{321} & 275 & 22 & \multirow{3}{*}{95} \\
\hline & & & 303 & 13 & \\
\hline & & & 229 & 32 & \\
\hline \multirow{3}{*}{ Lorazepam-d4 } & \multirow{3}{*}{8.41} & \multirow{3}{*}{325} & 279 & 22 & \multirow{3}{*}{105} \\
\hline & & & 307 & 13 & \\
\hline & & & 233 & 29 & \\
\hline
\end{tabular}

range of 1.0 to $10 \mathrm{ng} / \mathrm{mL}$ for lormetazepam and lorazepam, and of 2.5 to $25 \mathrm{ng} / \mathrm{mL}$ for nordiazepam. When levels were beyond the calibration range, the blood sample should be diluted. The limit of quantification with the used method was $1.0 \mathrm{ng} / \mathrm{mL}$ for lormetazepam and lorazepam, and $2.5 \mathrm{ng} / \mathrm{mL}$ for nordiazepam. A summary of the quantitative results appears in Table 2.

\section{Discussion}

The findings in Table 2 would reflect an intake of nordiazepam and lormetazepam. These are blood concentrations of drugs measured at the time of sampling, they cannot inform about the effects of the drugs at the moment of poisoning because sample collection did not square with the facts. Drugs would be broken down and significantly eliminated from the blood two days after ingesting. Even so, it is possible to estimate the initial concentrations by back-extrapolating from these actual concentrations. Considering the drugs were administered orally and fast absorbed by the body, first-order elimination can be used for calculation. Generally, with a first-order process of elimination, the amount of drug eliminated in a set amount of time is directly proportional to the amount of drug in the body [9]. The initial concentration $\left(C_{0}\right)$ at the relevant time can be calculated using the equation:

$$
C_{t}=C_{0} \mathrm{e}^{-k t}[10] \text { or } C_{0}=C_{t} / \mathrm{e}^{-k t}
$$

$C_{0}=$ initial concentration at the relevant time.

$C_{t}=$ concentration at time $t$ of sampling (residual concentration).

$t=$ time elapsed between sampling and moment of poisoning (in the present case $t=48 \mathrm{~h}$ ).

$k=$ elimination constant.

One way to calculate the elimination constant $k$ of drug is to have information about its half-life $\left(t_{1 / 2}\right)$. The elimination half-life $t_{1 / 2}$ of a medication refers to the time necessary for the drug to be reduced to half of its initial concentration in the body. By knowing half-life $t_{1 / 2}$ of the drug, its elimination constant $k$ can be given by: $k=\log (2) / t_{1 / 2}$ [10], where $\log$ is taken to base e (log neperien) giving a value of $\log (2)=0.693$.

Both nordiazepam and lormetazepam are from the same benzodiazepine family. Nordiazepam, is an anxiolytic drug, it can be prescribed for treatment of alcohol withdrawal symptoms with habitual daily dosage of 7.5 - 15 
Table 2. Blood concentrations of lormetazepam, lorazepam and nordiazepam at the moment of sampling (residual concentrations).

\begin{tabular}{cc}
\hline Drug & Found concentration $(\mathrm{ng} / \mathrm{mL})$ \\
\hline Lormetazepam & 6.8 \\
Lorazepam & 6.3 \\
Nordiazepam & 16.2 \\
\hline
\end{tabular}

mg [11]. It rapidly exhibits a peak plasma concentration within $1.5 \mathrm{~h}$ [11]. Its half-life can vary between 30 and $150 \mathrm{~h}$ with an average of $65 \mathrm{~h}$ [11]. Given that its half-life is relatively long, nordiazepam has less problem for its detecting even if sampling is late. Its therapeutic blood concentrations at steady-state were reported to range from $200-800 \mathrm{ng} / \mathrm{mL}$ [12]. In the present case, the residual concentration of nordiazepam $\left(C_{t}\right)$ measured in the blood is $16.2 \mathrm{ng} / \mathrm{mL}$; it is lower than the therapeutic range. In organism, nordiazepam is mainly metabolized to oxazepam. This metabolite, with a half-life of about $8 \mathrm{~h}$ [13], is not detected in the blood at the moment of sampling.

Lormetazepam, is used in treatment of insomnia with habitual daily dosage of 1 - $2 \mathrm{mg}$ [14]. It is rapidly absorbed and exhibits an average peak plasma concentration of about $6 \mathrm{ng} / \mathrm{mL}$ within $1.5 \mathrm{~h}$ after a single $1 \mathrm{mg}$ oral dose [14]. Lormetazepam is active with low concentration; its therapeutic blood concentrations at steady-state were reported to range from 2 - $10 \mathrm{ng} / \mathrm{mL}$ [12]. In organism, the drug is mainly metabolized to lorazepam [15]. Lormetazepam and lorazepam have short elimination half-lives of about $10 \mathrm{~h} \mathrm{[15]} \mathrm{[16]} \mathrm{and} 14 \mathrm{~h}$ [17] respectively. Due to their short half-lives, lormetazepam and lorazepam, are difficult to be detected in blood. In the present study, drugs would be quasi-completely removed from the body when victim was able to give up his blood. Hence, GC-MS and HPLC-DAD detected neither lormetazepam nor lorazepam in the blood. Fortunately, through the LC-MS/MS system, we were able to determine these two drugs in blood. The residual concentration of lormetazepam $(6.8 \mathrm{ng} / \mathrm{mL})$ is low, but it remains active for two days following ingestion, it is within the therapeutic range (Table 3). As for lorazepam, its residual concentration $(6.3 \mathrm{ng} / \mathrm{mL})$ is lower than the therapeutic concentration (Table 3), thus it was inactive.

By knowing the residual concentrations $\left(C_{t}\right)$ and half-lives $\left(t_{1 / 2}\right)$ of lormetazepam, lorazepam and nordiazepam, the initial concentration $\left(C_{0}\right)$ of each drug has been estimated by an extrapolation approach using the formula described earlier: $C_{0}=C_{t} / \mathrm{e}^{-k t}$ [10]. The extrapolating results are illustrated in Table 3. By referencing to data range, the initial concentration $\left(C_{0}\right)$ of lormetazepam in blood $(189 \mathrm{ng} / \mathrm{mL})$ is 18.9 times higher than the limit of therapeutic level (2 - $10 \mathrm{ng} / \mathrm{mL})$ [12], and 1.89 times higher than the toxic level (100 ng/mL) [12]. The initial concentration $\left(C_{0}\right)$ of lorazepam in blood $(68 \mathrm{ng} / \mathrm{mL})$, was in the therapeutic range (20 - $\left.250 \mathrm{ng} / \mathrm{mL}\right)$ [12]. The initial concentration $\left(C_{0}\right)$ of nordiazepam in blood $(27 \mathrm{ng} / \mathrm{mL})$ was inactive. Seeing that the half-life of nordiazepam can vary considerably between individuals (30 - $150 \mathrm{~h}$ ), it would be useful to calculate a range of initial drug concentration. After calculating by the formula, the initial concentrations of nordiazepam $\left(C_{0}\right)$ can range from 20 to $49 \mathrm{ng} / \mathrm{mL}$. The highest concentration of $49 \mathrm{ng} / \mathrm{mL}$ remains inactive; for that reason we think the average drug half-life can be used for the calculation. For oxazepam, considering that its residual concentration $\left(C_{t}\right)$ is unknown, it is not possible to calculate the concentration $\left(C_{0}\right)$ at the time of poisoning. Under the conditions described above, the quantification limit of oxazepam was $1.0 \mathrm{ng} / \mathrm{mL}$ using oxazepam-d5 as internal standard. In hypothesis testing, we tentatively assume that concentration $\left(C_{t}\right)$ of oxazepam could reach this threshold. Basing on this maximalist approach, the concentration $\left(C_{0}\right)$ of the drug can be estimated to be $64 \mathrm{ng} / \mathrm{mL}$, which is below a clinical therapeutic range (Table 3). Only lormetazepam and lorazepam were active at that moment. Consequently, at the relevant moment, the victim was under the effects of lormetazepam and lorazepam. The sum of both drugs (lormetazepam + lorazepam) in blood concentration, can bring an additive effect. Other factors such are: dose, clinical status and individual susceptibility to the drug, would influence on degree of the symptoms. The ingested quantity of drug was unknown, but according to the husband, only a 2 mg tablet of Noctamide ${ }^{\circledR}$ (lormetazepam) was given. He needed to help his wife get better sleep, and so, he given his own medication to her. This is a maximum accepted dose [15] for treatment by lormetazepam. Obviously, the case is a poisoning by lormetazepam. 
Table 3. The extrapolating results in comparison with database.

\begin{tabular}{|c|c|c|c|c|c|}
\hline Drug & $\begin{array}{l}\text { Residual concentration } \\
\text { at time of sampling } \\
(\mathrm{ng} / \mathrm{mL}) C_{t}\end{array}$ & $\begin{array}{l}\text { Mean half-life (h) } \\
t_{1 / 2}\end{array}$ & $\begin{array}{l}\text { Elimination } \\
\text { constant } \\
k=\log (2) / t_{1 / 2}\end{array}$ & $\begin{array}{l}\text { Initial concentration } \\
48 \mathrm{~h} \text { prior to sampling } \\
(\mathrm{ng} / \mathrm{mL}) C_{0}=C_{t} / \mathrm{e}^{-k t}\end{array}$ & $\begin{array}{l}\text { Blood concentration from } \\
\text { database }(\mathrm{ng} / \mathrm{mL})\end{array}$ \\
\hline Lormetazepam & 6.8 & $10[16]$ & $\begin{array}{l}0.693 / 10 \\
=0.0693\end{array}$ & $\begin{array}{c}6.8 / \mathrm{e}^{-(0.0693) 48} \\
6.8 / 0.036 \\
=189\end{array}$ & $\begin{array}{l}\text { Therapeutic: } 2 \text { - } 10 \text { [12] } \\
\text { Toxic: } 100 \text { [12] }\end{array}$ \\
\hline Lorazepam & 6.3 & $14[17]$ & $\begin{array}{l}0.693 / 14 \\
=0.0495\end{array}$ & $\begin{array}{l}6.3 / \mathrm{e}^{-(0.0495) 48} \\
6.3 / 0.093 \\
=68\end{array}$ & $\begin{array}{l}\text { Therapeutic: } 20 \text { - } 250 \text { [12] } \\
\text { Toxic: } 300 \text { - } 500 \text { [12] }\end{array}$ \\
\hline Nordiazepam & 16.2 & $65[11]$ & $\begin{array}{l}0.693 / 65 \\
=0.0106\end{array}$ & $\begin{array}{l}16.2 / \mathrm{e}^{-(0.0106) 48} \\
16.2 / 0.6 \\
=27\end{array}$ & $\begin{array}{l}\text { Therapeutic: } 200 \text { - } 800 \text { [12] } \\
\text { Toxic: } 1500 \text { - } 2000 \text { [12] }\end{array}$ \\
\hline Oxazepam & $\begin{array}{l}\text { Assumed to be } 1.0 \\
\text { (limit of quantification) }\end{array}$ & 8 [13] & $\begin{array}{c}0.693 / 8 \\
=0.0866\end{array}$ & $\begin{array}{l}1.0 / \mathrm{e}^{-(0.0866) 48} \\
1.0 / 0.0156 \\
=64\end{array}$ & $\begin{array}{l}\text { Therapeutic: } 200 \text { - } 1500 \text { [12] } \\
\text { Toxic: } 2000 \text { [12] }\end{array}$ \\
\hline
\end{tabular}

\section{Conclusion}

This report documents a case of intentional poisoning by lormetazepam in which effect of the drug interferes with that of nordiazepam which is prescribed as medication. The initial concentration of lormetazepam estimated in blood (189 $\mathrm{ng} / \mathrm{mL})$, is toxic. Without sensitive method that is however more expensive, it is not able to obtain outcomes that are favorable to legal services. How justice in poor countries may be able to prove the truth?

\section{References}

[1] Substance Abuse and Mental Health Services Administration, Center for Behavioral Health Quality and Statistics (2013) The DAWN Report. Update on Drug-Related Emergency Department Visits Attributed to Intentional Poisoning. Rockville.

[2] Lemmer, P., Schneider, S., Mühe, A. and Wennig, R. (2007) Quantification of Lorazepam and Lormetazepam in Human Breast Milk Using GC-MS in the Negative Chemical Ionization Mode. Journal of Analytical Toxicology, 31, 224226. http://dx.doi.org/10.1093/jat/31.4.224

[3] Cabarcos, P., Tabernero, M.J., Alvarez, I., Lopez, P., Fernandez, P. and Bermejo, A.M. (2010) Analysis of Six Benzodiazepines in Vitreous Humor by High Performance Liquid Chromatography-Photodiode-Array Detection. Journal of Analytical Toxicology, 34, 539-542. http://dx.doi.org/10.1093/jat/34.9.539

[4] Smink, B.E., Mathijssen, M.P.M., Lusthof, K.J., De Gier, J.J., Egberts, A.C.G. and Uges, D.R.A. (2006) Comparison of Urine and Oral Fluid as Matrices for Screening of Thirty-Three Benzodiazepines and Benzodiazepine-Like Substances Using Immunoassay and LC-MS(-MS). Journal of Analytical Toxicology, 30, 478-485. http://dx.doi.org/10.1093/jat/30.7.478

[5] Schreiber, A., Houssain, E.A. and Gibbons, J. (2009) A Fast and Sensitive LC/MS/MS Method for the Quantitation and Confirmation of 30 Benzodiazepines and Nonbenzodiazepines Hypnotics in Forensic Urine Samples. Applied Biosystems. Application Note. Cliquid Drug Screen \& Quant Software for Routine Forensic Toxicology, 1-6.

[6] McHale, K.J., Ho, J. and Springfield, A. (2007) A Quantitative Screen for Multiple Classes of Illicit Drugs and Their Primary Metabolites in Human Biological Fluids by LC-MS/MS. Thermo Fisher Scientific, Application Note 390.

[7] Pok, P.-R.P., Mauras, M., De Saint Léger, M.-N., Kuhlmann, E., Charpenel-Durat, C., et al. (2010) Blood Concentration of Clobazam and Norclobazam in a Lethal Case Involving Clobazam, Meprobamate and Clorazepate. Legal Medicine, 12, 300-304. http://dx.doi.org/10.1016/j.legalmed.2010.08.002

[8] Pok, P.-R.P. (2013) Some Worlds about Postmortem Blood Atropine Concentrations. Forensic Medicine and Anatomy Research, 1, 37-39. http://dx.doi.org/10.4236/fmar.2013.13007

[9] Dipiro, J.T., Spruill, W.J., Wade, W.E., Boulin, R.A. and Pruemer, J.M. (2010) Concept in Clinical Pharmacokinetics. 5th Edition, ASHP, Lesson 2, 19-27.

[10] (2012) Half-Life. Drugs Forum. http://www.drugs-forum.com/forum/showwiki.php?title=Half-life

[11] Vidal ${ }^{\circledR}$ (2012) Les monographies des spécialités pharmaceutiques du Dictionnaire Vidal ${ }^{\circledR}$. 88th Edition, Vidal, France, 
Nordaz $^{\circledR}, 1577-1578$.

[12] Schulz, M., Iwersen-Bergmann, S., Anderson, H. and Schmoldt, A. (2012) Therapeutic and Toxic Blood Concentrations of Nearly 1000 Drugs and Other Xenobiotics. Critical Care, 16, R136. http://ccforum.com/content/16/4/r136 http://dx.doi.org/10.1186/cc11441

[13] Vidal $^{\circledR}$ (2012) Les monographies des spécialités pharmaceutiques du Dictionnaire Vidal ${ }^{\circledR}$. 88th Edition, Vidal, France, Seresta $^{\circledR}, 2044-2045$.

[14] Zentiva, Lormetazepam 1 mg Tablets. http://www.medicines.org.uk/emc/medicine/28193/SPC

[15] Vidal ${ }^{\circledR}$ (2012) Les monographies des spécialités pharmaceutiques du Dictionnaire Vidal ${ }^{\circledR}$. 88th Edition, Vidal, France, Noctamide $^{\circledR}, 1572-1573$.

[16] Moffat, A.C., Osselton, M.D. and Widdop, B. (2004) Clarke's Analysis of Drugs and Poisons in Pharmaceuticals, Body Fluids and Postmortem Material. 3rd Edition, Pharmaceutical Press, Lormetazepam, London, 1189-1190.

[17] Moffat, A.C., Osselton, M.D. and Widdop, B. (2004) Clarke's Analysis of Drugs and Poisons in Pharmaceuticals, Body Fluids and Postmortem Material. 3rd Edition, Pharmaceutical Press, Lorazepam, London, 1187-1188. 
Scientific Research Publishing (SCIRP) is one of the largest Open Access journal publishers. It is currently publishing more than 200 open access, online, peer-reviewed journals covering a wide range of academic disciplines. SCIRP serves the worldwide academic communities and contributes to the progress and application of science with its publication.

Other selected journals from SCIRP are listed as below. Submit your manuscript to us via either submit@scirp.org or Online Submission Portal.
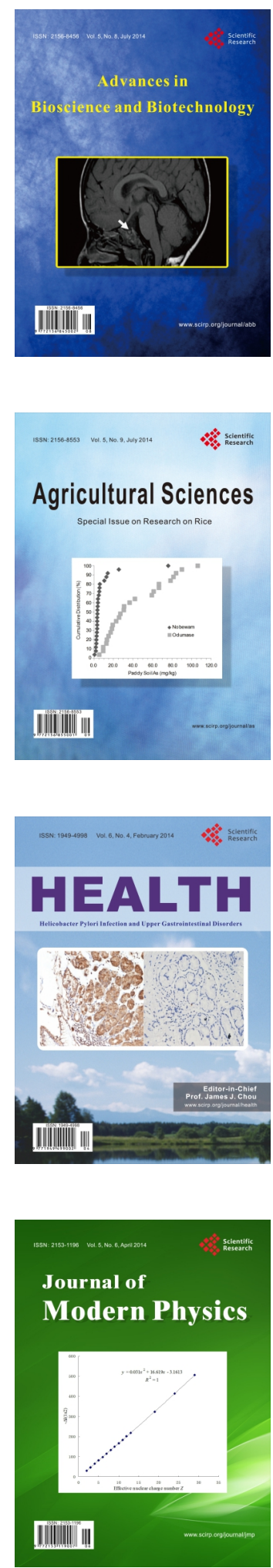
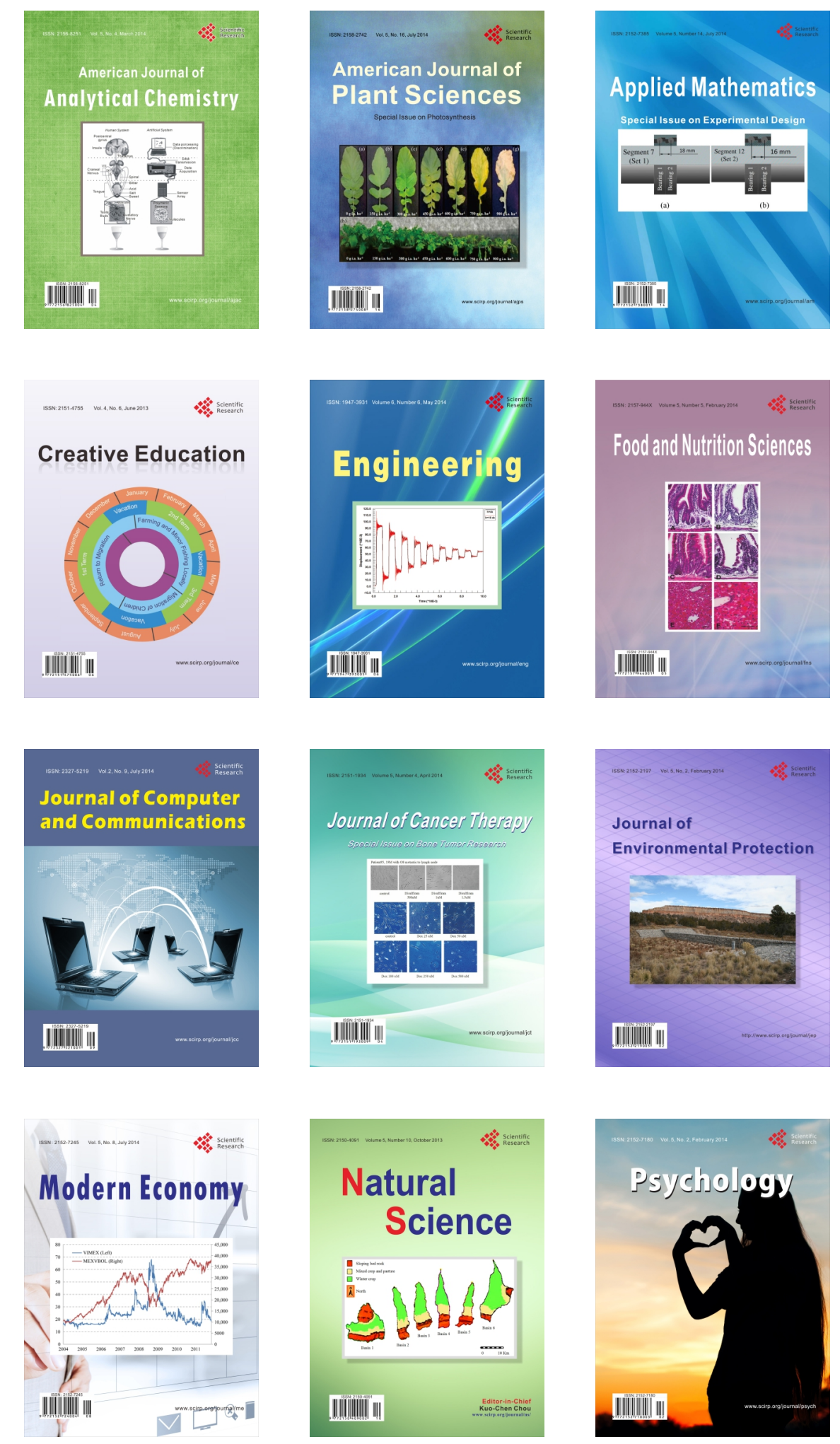